Experentia (Ingenio), que apreciamos en la estampa mediante un dedo señalando la cabeza y en tapiz por una figura femenina que observa su mano (figs.13 y 14). La lámina, en su parte inferior, dispone un ave manteniendo el vuelo para poder beber de la estrecha boca de una jarra, aspecto que observamos con el mismo sentido en la divisa de los impresores Francisco y Diego Fernández de Córdoba (s. xvI). En el grabado leemos Industria numen fauet (C.E.5099).

Architectupa (Arquitectura) (figs. 15 y 16) aparece con el compás, la regla, la escuadra y el mazo, elementos comunes a esta disciplina como observamos en tapiz sobre las artes que hemos comentado donde también se dispone el mazo, elemento que se manifiesta en la zona inferior de la estampa. El lema nos dice Architectura urbium ornamentum (C.E.5100).

Poesis (Poesía) (figs. 17 y 18). La estampa, como el tapiz, nos presenta el libro y el pergamino, aquella incorpora en la zona inferior un cisne, este último en referencia a la musa Clio como observamos en las estampas del Tarot en referencia a la Poesía. El lema nos dice Dignum laude virum Musae vetat mori (C.E.5101).

Como podemos apreciar en este sucinto comentario, la estampa propone modelos que las artes en general tomaron como fuente, pero también considera y define atributos que nos permiten conocer e identificar imágenes, definir ideas que se traducen por lo visual. Este es un aspecto importante en el que entiendo debemos detenernos para divulgar imágenes fundamentadas en los soportes literarios que las construyen y en el visual que las difunde. Aquí, aunque dificultoso, encontramos un importante reto que nos lleva a no conformarnos con la simple y mera identidad formal con otras manifestaciones artísticas tenidas por más o menos nobles, más bien a trascender al suceso semántico con que una y otra vez nos asaltan las artes del bien llamado Humanismo.

Jesús María GonZÁLez de ZáRate Universidad del País Vasco

\title{
LOS PROYECTOS DEL ARQUITECTO FRANCÉS MANSART DE SAGONNE PARA LOS CANALES DEL EBRO Y DEL MANZANARES (1768)
}

La llegada del arquitecto francés Jacques Hardouin-Mansart de Sagonne (1711-1778), nieto del gran arquitecto de Luis XIV Jules Hardouin-Mansart, a Madrid durante el verano de 1768 provocó la evolución, poco más o menos voluntaria, según los casos, de unos proyectos de arquitectura o de ingeniería que la administración del rey Carlos III había descuidado desde hacía años. Si esa llegada constituye un episodio totalmente desconocido de la historia de los canales de España por los autores españoles, su análisis permite no obstante medir el interés que tenían unos ingenieros franceses para un país - España- muy descuidado en aquella época y muy atrasado en el plano de las comunicaciones interiores. Sobre todo, es muy instructivo comparar la política de ambos países - Francia y España - ligados por un Pacto de Familia, en cuanto a las concesiones de privilegios para la construcción y la explotación de canales de navegación. Los proyectos de Mansart de Sagonne son emblemáticos de la política resuelta de Carlos III en materia de infraestructuras fluviales favorecida por un tratado de comercio en enero de 1768 . 


\section{1) La actividad de Mansart de Sagonne en Francia y en España}

En 1768, cuando llegó a Madrid, la situación personal del artista era poco brillante. Él, que era arquitecto de la Real Academia de Arquitectura de París, ingeniero ordinario del rey y primer arquitecto de los Estados de Borgoña y que había conocido su período de gloria hasta mediado el año 1750, se había encontrado de repente arruinado y todos sus bienes secuestrados. Mansart de Sagonne, que llevaba también el apellido de Mansart de Lévy —el que llevó en España-, había sido encargado por Luis XV de construir la espléndida iglesia de San Luis de Versalles - entonces capital de Francia- y que dominaba la ciudad en toda su masa y altura. Este arquitecto había construido también para numerosas personas eminentes de la corte, como el conde de Saint-Florentin, potente ministro del gobierno de Luis XV durante todo su reinado y gran amigo suyo, en París; para el conde de Clermont, príncipe de sangre real, primo del rey de Francia, en la abadía de Saint-Germain-des-Prés en París...; o para príncipes extranjeros tal como el duque de Dos-Puentes, príncipe palatino, en su palacio de Jagesburg sobre el Rin, por ejemplo.

Trabajaba en el estilo rococó francés que durante los años 1750 había pasado de moda en provecho del estilo neoclásico, al que no se adaptó. Es en ese estilo rococó como había dibujado los proyectos para las plazas reales de París y de Marsella; esta última estuvo a punto de realizarse.

Artista pasado de moda, había previsto desde 1756 proseguir su carrera en la península al proponer sus servicios al rey de Portugal, José I, con un proyecto de reconstrucción del palacio real de Lisboa después del terremoto de 1755. Sus dificultades personales se lo habían impedido, pero ese proyecto lo tenía en la mente en 1768, por si acaso los proyectos para el rey de España no le hubiesen convenido.

Un mal pleito a propósito de los bosques de su tierra de Lévy, en el centro de Francia (Allier), con una compañía privada y que duró diez años (1754-1764), le había arruinado definitivamente. Sus acreedores le perseguían y había tenido que refugiarse en 1764 en el hotel del príncipe de Conti, en el recinto del Templo, en París. En 1766, pidió de nuevo el pasaporte que se le había otorgado en 1756 para marcharse a Lisboa. Consciente de que eso pudiese ser un medio para huir de sus acreedores, el director de las Construcciones del rey, el marqués de Marigny, hermano de Madame de Pompadour, por fin se lo otorgó gacias al potente apoyo del ministro Saint-Florentin, su mayor protector.

Fue a fines de 1767 cuando se decidió a marcharse al sudoeste de Francia ${ }^{1}$. Acababa de conocer un nuevo fracaso en uno de sus diversos proyectos de canales en Francia, el del Essonne, afluente del Sena, que fue rechazado por una real cédula de mayo de 1767. Empezó por dirigirse hacia Tolosa, ciudad de la familia de su madre y luego hacia el País Vasco, en Bayona más precisamente, para encontrar a otros miembros de su familia. Esa estancia estaba sobre todo destinada a examinar el terreno, por el lado español, para su proyecto de canal de navegación sobre el río Ebro.

A pesar de ser un hombre sufrido, arruinado y decepcionado, tenía sin embargo mucha confianza en el porvenir y en su proyecto, llegando a Madrid a principios de Julio de 1768 . Había viajado hasta entonces bajo el seudónimo de «conde de Cernay», pero aquí pudo tomar de nuevo su verdadera identidad. Vivía en la fonda de San Sebastián, enfrente a la iglesia, que

\footnotetext{
1 Había confiado la gestión de sus asuntos a un señor llamado De George: «intérésse dans les affaires du roi», en París, cuya correspondencia con Mansart fue secuestrada durante la Revolución Francesa. Conservada en los Archives Nationales con el número T 168/3, ésta nos ha permitido conocer todo el detalle de la estancia de Mansart en Madrid.

${ }^{2}$ Dice: «J'ay été assez bien accueilli et j'ay lieu de croire que mes entreprises tourneront à bien»; París, Archives Nationales, T 1168/3, carta del 7 de julio de 1768 a De George.
} 
pertenecía al señor Gepini ${ }^{3}$. Para presentarse al rey, él dice que había ordenado un traje negro de tela de Amiens. Vivió en Madrid con muy poco dinero, gracias a una carta de cambio de mil libras que había tenido que hacer a una persona que conocía en Bayona, antes de su salida. Mansart se quejó de la carestía de la vida, que «l'on y donne tout au faste, a l'hypocrisie, et à la futilité» ${ }^{4}$.

Llegó a la capital española con la recomendación del conde de Saint-Florentin para el marqués de Ossun, embajador de Francia. El arquitecto trabó numerosos contactos antes de su presentación al rey, el 19 de julio. Siguió a la corte real en todos sus viajes a San Lorenzo del Escorial y a La Granja, lo que le ocasionó numerosos viajes muy costosos. Así pudo remitir una memoria de sus proyectos presentada al rey por una persona de importancia ${ }^{5}$ y que fue, dice, bien recibida y acogida. Carlos III había dicho, a la vista de esa memoria, según Mansart, con un aire gracioso: «voilà de grandes et belles idées je veroy cela en son temps, il faut les laissés venir» ${ }^{6}$.

La memoria constaba de cinco proposiciones:

$1 .^{\circ}$ ) «Faire le bastiment des nobles, hospital encomencé par le feü Roy». El arquitecto francés alude al hospital general de Madrid cuyo proyecto se confió al arquitecto don José de Hermosilla y Sandoval por Fernando VI. Empezadas en marzo de 1758, las obras permanecieron sin acabarse diez años después, cuando llegó Mansart en 1768. Sólo se edificó el piso bajo de un ala ${ }^{7}$. Poco después de esa entrevista, el 24 de julio, el Consejo de Castilla otorgó dos millones de reales, tomados en los bienes secuestrados de los jesuitas, para reactivar el proyecto ${ }^{8}$.

2. ${ }^{\circ}$ Crear un canal de navegación para unir el Atlántico al Mediterráneo que estudiaremos más adelante.

$3 .^{\circ}$ Un plan de financiación para llevar a cabo el dicho proyecto.

4..$^{\circ}$ Un plan para la agricultura ${ }^{9}$.

$5 .^{\circ}$ ) La construcción de un nuevo tipo de nave ${ }^{10}$.

Claro que no se trataba de realizar, como dice, todos esos proyectos sino de proponer varios para merecer la mayor atención del monarca español sobre uno de ellos. En efecto, durante su entrevista con el rey, el marqués de Grimaldi, presidente del Consejo, y el embajador de Francia, ese día 19 de julio de 1768, Carlos III se mostró muy interesado por su proyecto de canal sobre el río Ebro y le propuso también hacer el del Manzánares.

\footnotetext{
${ }^{3}$ Una placa puesta en el edificio que se sitúa en el antiguo sitio de esa fonda por el Ayuntamiento de Madrid en 1991, asegura que numerosas personalidades ilustradas se reunían allí, bajo el reinado de Carlos III. Por consiguiente, esa era una estupenda ocasión para Mansart de tratar de sus proyectos y de establecer relaciones.

${ }^{4}$ Dice a propósito de eso en una carta del 16 de agosto durante su salida: «Le deffaut seul d'argent me cause des entraves et me recule, n'ayans pas le sol (...); je cache ma façon de m'en aller d'icy, a tout le monde, je paye des dehors fastueux pour sauver les apparences, dieu soit en mon ayde: je pars donc après demain avec un air d'aisance jusqu'à la Iere poste, (...) avec 6 louis dans ma poche (...); voila mon état avec l'apparence de la plus brillante fortune, et dois me rendre à Bordeaux».

${ }^{5}$ Es decir, el marqués de Ossun.

${ }^{6}$ Palabras formuladas en la carta del embajador a Mansart y que el arquitecto escribió al marqués de Marigny, director de las Construcciones Reales, en su carta del 27 de marzo de 1769, en Burdeos; París, Archives Naitonales, 0/I/1911/2, n. ${ }^{\circ} 72$.

7 Mansart proponía ese proyecto después de su experiencia al Hotel-Dieu de Marsella en 1753 del que dibujó los planos y elevaciones y de los que sólo un cuarto de ellos se realizaron.

${ }^{8}$ Jacques Soubeyroux: Paupérisme et rapports sociaux à Madrid au XVIIIe siècle, Lille, 1978, 2vol., p. 540.

${ }^{9}$ Mansart alude sin duda a su «eau végétative» (agua vegetativa), especie de abono que permitía la producción intensiva de cereales. Defenderá su fórmula delante de la Real Academia de Ciencias de París en 1776.

${ }^{10}$ Hace referencia a su proyecto de nave sin vela y remos que propondrá al rey Luis XVI en 1776.
} 
2) Detalles de los proyectos de Mansart de Sagonne para el Canal del Ebro y del Canal del Manzanares

a) El canal del río Ebro

Con ese canal, Mansart quería crear un canal paralelo al canal de Languedoc por el lado español, a fin de que se evite el estrecho de Gibraltar que se dejaba entonces en las manos enemigas de los ingleses. Quería también acortar el camino de 700 a 800 leguas. Por eso creaba un pequeño brazo de canal de 9 leguas poco más o menos, desde San Sebastián hasta Segura, en la provincia de Guipúzcoa, a lo largo del río Oria; este pueblo constituía el punto divisorio para unirse con el Ebro. Proyectaba cavar el cauce del río en unas veinte leguas a fin de que pudiesen navegar las naves hasta el Mediterráneo. Para llevar a cabo esa empresa, proponía al rey: $1 .^{\circ}$ ) el establecimiento de una lotería real con una compañía de París; $2 .^{\circ}$ ) o una tontina de 96 millones de libras con una lotería y la posibilidad de encontrar a personas que sustituyeran a los accionistas fallecidos. El arquitecto estimaba el coste de su proyecto para la corona española, con todos los gastos pagados, a 158 millones de libras durante unos veinte años. Además, declaraba que los ingenieros del rey habían considerado sus planos y memorias.

\section{b) El canal del río Manzanares}

En cuanto al canal del Manzanares, Mansart declaró que fue realizada una parte en una distancia de ocho leguas en Castilla la Vieja, y que se paró ahí por la ignorancia del ingeniero. Él hacía pasar su propio canal por San Ildefonso y lo conducía a través de Madrid para reunirse con el Tajo al cambiar la mitad del cauce del Manzanares, que era muy malo. Por ese trazado conseguía un desnivel muy ventajoso con más de 800 a 900 pies de declive en 25 leguas. Dijo que se encontró ese proyecto muy bonito y que fue aplaudido por toda la gente, y se quería empezar ya su construcción. Así ese canal permitía mejorar el suministro de la capital ${ }^{11}$. Por supuesto, tenía un verdadero interés económico ya que podía producir, según los datos de Mansart, unos 40 millones de libras al año, e incluso 600 mil libras más, a partir del segundo año, con el riego de las tierras para las que podía usarse también.

De un modo general, ambos proyectos se apreciaron mucho y se deseaba verlos realizados. Por eso, Carlos III traspasaba a Mansart la realización y la explotación del canal del Manzanares caído en el abandono. El rey explicó a Mansart que la corona no tenía mucho dinero para financiar operaciones como éstas después de todo lo que había gastado en empresas desde el principio de su reinado. Puso el arquitecto sus proyectos en las manos del Consejo de Castilla para negociar al detalle las operaciones y aprobar la decisión del rey, y así fue registrada. El rey le traspasaba no sólo los derechos de aranceles para la navegación, sino también los de riego que, según Mansart, eran cuantiosos.

El 20 de julio de 1768, el marqués de Grimaldi escribió al conde de Aranda, gobernador del Consejo de Castilla, en San Lorenzo del Escorial, que: «se ha presentado al rey por parte de Mr. Mansart de Levy conde de Sagona: $1 .^{\circ}$ una Memoria en que se ofrece a la grande empresa de comunicar el Mediterraneo y el Oceano en España, por un canal, como sucede en francia por el de Languedoc, y casi todas las Provincias de España unas con otras por otros dife-

"La corte sólo consumía unas 200.000 tm. de mercancías al año, y en 1766-1768 Madrid tenía 160.000 habitantes. Véase el artículo de Santos Madrazo: «Madrid: Ciudad y territorio en la época de Carlos III» en Carlos III Alcalde de Madrid, catálogo de la exposición del Ayuntamiento de Madrid bajo la dirección de Carlos Sambricio, Madrid, 1988, pp. 109 a 126 
rentes canales, y $2 .^{\circ}$ otro papel de condiciones que pide para efectuarla, formando una compañía que la costee» ${ }^{12}$.

Aunque estuviese un poco encolerizado contra la lentitud administrativa del Consejo, Mansart vio sus proyectos aprobados y registrados por dicho Consejo a principios del mes de agosto de 1768. Luego se pusó en marcha hacia Francia, provisto de las cartas del marqués de Grimaldi y del marqués de Ossun, así como de un pasaporte procedente de San Ildefonso, para constituir una firme compañía con 30 millones de libras de fondos ${ }^{13}$. Se marchó el 18 de agosto para Burdeos, Montpellier y Holanda, porque le parecía que una compañía como ésa no podía constituirse sólo en Francia.

Así España se convirtió para él en un verdadero Eldorado, ya que las necesidades en materia de comunicaciones interiores eran enormes. Decía tener mucha esperanza en ese país donde «il y a des fortunes immenses à faire en ce Royaume». Añadía: «il y a ici gros à gagner l'on y est très pauvre a force d'y être riche». Además se alegraba de que, después de períodos tan difíciles como los que tuvo que atravesar en Francia, por fin pudiese estar personalmente en la más alta consideración, al entregar al señor de George las cartas que probaban que toda la gente estaba convencida de la solidez de sus talentos.

\section{3) Análisis político y económico de los proyectos de canales de Mansart de Sagonne en España}

\section{a) El canal del río Ebro}

El canal de Mansart en el río Ebro evoca, claro, el Canal Imperial de Aragón del que Carlos III acababa de traspasar los derechos a los franceses Jean Augustin Badin y a su hijo Louis Michel, por cédula real del 28 de febrero de 1768, o sea cinco meses antes de la llegada de nuestro arquitecto a Madrid ${ }^{14}$. Según unos historiadores, el proyecto propuesto por Badin no correspondía mucho a las esperanzas del rey que deseaba la creación de un canal comunicando el Atlántico con el Mediterráneo ${ }^{15}$. Ahora bien, el proyecto de Jean Augustin Badin no quería más que transformar un antiguo canal de riego concebido en el siglo xvi, bajo el reino de Carlos V, y llamado «Azequia Imperial de Aragón», en un canal de návegación uniendo Tudela, en Navarra, con los alrededores de Zaragoza. La anchura del canal, realizado entre 1770 y 1790 , se prolongará, durante el siglo XIX, de modo más ambicioso por una vía de ferrocarril desde Zaragoza hasta el Atlántico.

El trazado que propuso Mansart para su canal desde el Atlántico hasta el Ebro ya se conocía desde el siglo XVI ${ }^{16}$ y ese canal tenía que servir también de canal de riego. Es por eso por lo que en su carta a Aranda, del 20 de julio, Grimaldi aludió a esos diversos canales que tenían

\footnotetext{
12 Madrid, Archivo Histórico Nacional: Consejos, libro 809 (1768), folio 34, n. 82.

${ }_{13}$ Cuando llegó a Madrid, Mansart de Sagonne había evocado la necesidad de una compañía de 7 a 10 millones de fondos sólo para el canal del Ebro que, aumentada con la del canal del Manzanares, sube hasta los 30 millones de fondos.

14 Jean-Augustin Badin, comisario de guerra de las reales armadas francesas, llegó a Madrid en 1766 para presentar a Carlos III su proyecto de canal sobre el Ebro. Véase Luis Gonzales Rodrigo: Historia del Canal Imperial de Aragón, Zaragoza, 1984, p. 139.

15 Véase la nota 14 y al artículo anónimo: «Noticias importantes sobre canales de navegación y riego en España», en Continuación del Almacén de Frutos Literarios o Semanario de obras inéditas, tomo III, Madrid, 1818 , pp. 249 a 263.

${ }_{16}$ Evarista Correa Calderón cita, en Registro de arbitristas, economistas y reformadores españoles (1500-1936), Madrid, 1981, p. 83, n. ${ }^{\circ} 345$, un manuscrito anónimo del siglo xvi que tiene como título: «Canal navegable desde el mar Mediterráneo al Océano Cantábrico, continuando el proyecto del Reyno de Aragón, cruzando el de Navarra y la provincia de Guipúzcoa por los ríos Arga y Oria, reunidos por varios manantiales y depósitos de agua en la altura de Lecumberri».
} 
que penetrar las provincias de España a lo largo del recorrido de dicho canal. Aranda debía encontrarse tanto más sensible al proyecto de Mansart como jefe del partido aragonés, porque su trazado constituía una revalorización de su provincia de nacimiento. Carlos III había confiado el asunto a Aranda, y Mansart quería satisfacerles lo más que pudiera.

De todas formas, estaba claro que, además de su impacto económico, el canal tenía ante todo y sobre todo un interés más estratégico. Al evitar a las naves rodear la península y pasar por el estrecho de Gibraltar, Mansart privaba a los ingleses de una parte cuantiosa del interés estratégico y económico de dicho estrecho. Los aranceles percibidos para la travesía del canal habrían facilitado una fuente inestimable de ganancias para el reino de España, sin pagar nada, ya que la construcción y la explotación se concedían a una compañía privada.

En este punto, Carlos III y el Consejo de Castilla tenían que estar muy atentos a la viabilidad financiera de la compañía encargada de la creación del canal. En efecto, la de Badin conoció importantes fallos en este campo y tuvo que recurrir a los hacendistas holandeses Mansart no recurría a Holanda para su propia compañía- para empezar las obras del Canal Imperial de Aragón dos años después de la real cédula de 1768. Con una compañía válida para la financiación, el proyecto de Mansart sobre el Ebro habría satisfecho a Carlos III en cuanto a su trazado y su financiación. Se puede pensar que si Mansart hubiese vuelto en 1769, cuando Badin tenía dificultades de hacienda en su compañía, el rey le habría traspasado sin duda los derechos otorgados a Badin en 1768.

\section{b) El canal del río Manzanares}

Igual que el Canal Imperial de Aragón, la idea de un canal de navegación sobre el río Manzanares no era nueva, ya que desde el siglo Xvi el ingeniero de Felipe II don Juan Bautista Antonelli había propuesto tal solución para unir Madrid al Atlántico, haciendo de ella el gran puerto fluvial de la Península. Los conocimientos técnicos de entonces no habían permitido su realización. El interés por ese canal se reactivó bajo Fernando VI, que autorizó en 1756 a don Carlos de Simeón Pontera a formar una compañía ${ }^{17}$. Al final parece que fueron los ingenieros don José Briz, don Pedro Simó Gil, asociados con don Miguel Fernández Olmo, quienes iniciaron las primeras obras ${ }^{18}$. Mansart no pudo formar su compañía dentro de los tiempos impuestos por Carlos III y el rey decidió al final traspasar los derechos del canal a don Pedro Martinengo, por cédula real del 15 de mayo de $1770^{19}$. Se percibe en la rapidez de la real decisión la verdadera voluntad de Carlos III de modernizar el país a toda costa.

Eso nos permite comparar el método de los reinos de Francia y de España en la cesión de los privilegios para la construcción de canales. El caso de Mansart de Sagonne es muy significativo. He aquí un arquitecto e ingeniero real que nunca cesó de elaborar diversos canales de navegación para Francia: concibió sucesivamente un proyecto de canal sobre el Marna (1752); el Esonne,

\footnotetext{
${ }_{17}$ Hay que recordar que la política de canalización de los grandes ríos españoles se empezó bajo el reino de Fernando VI, con la llegada emblemática del francés Charles Lemaur en 1750 para el canal de Castilla, gracias a la intervención personal de su ministro, el marqués de la Ensenada.

18 José María Sanz García: «Los canales del Guadarrama y Manzanares de Juan II a Juan Carlos I pasando por Carlos III», en Aula de Cultura. Ciclo de conferencias: El Madrid de Carlos III, n. ${ }^{\circ} 11$, Ayuntamiento de Madrid, Instituto de Estudios Madrileños del Consejo Superior de Investigaciones Científicas, Madrid, 1988, p. 45.

${ }_{19}$ Madrid, Archivo Histórico: Sección 3, legajo 285, n. ${ }^{\circ} 1$ : «Certificación de una real cédula de 15 de mayo aprobando la propuesta hecha por D. Pedro Martinengo y Compañía sobre hacer un canal navegable desde el Puente de Toledo con aguas del Río Manzanares». Desde octubre de 1769 ese «ingeniero» había sometido a Grimaldi su proyecto para el dicho canal. Fue realizado en parte desde el puente de Toledo y recorrió la orilla izquierda del Manzanares para acabarse en 1818 en la Casa del Mayorazgo en Vallecas.
} 
afluente del Sena (1759-1767); en Borgoña (1763-1764); en Champaña (1764), que todos fracasaron. En todos estos casos, la competencia para conseguir la cesión era muy encarnizada ya, lo que permitía a la real administración francesa ya no cesar los derechos sea quien sea. Para ganar tiempo y disuadir a estafadores, volvía a estudiar constantemente los expedientes y repetía varias veces el mismo proceso ${ }^{20}$. Así, después del fracaso del canal del Essonne, en mayo de 1767, Mansart se decidió al final a probar fortuna en los canales extranjeros.

En España no ocurrió nada de eso. Carlos III tomó conciencia de la revolución del transporte que se iniciaba y del retraso en comparación con países como Inglaterra, que acababa de abrir el Saukley Brook (1757) y el canal del duque de Bridgewater (1759); pero sobre todo, como Francia tenía la red más desarrollada de Europa con los canales de Languedoc y de Briare (siglo XVII). También se estudiaron numerosos canales sobre los ríos franceses, de los cuales los de Borgoña y de Provencia eran los más ambiciosos. El rey sabía también que en ese campo España no tenía precedentes recientes. Tomaba conciencia, como déspota ilustrado, de que una de las llaves del desarrollo económico era el dominio y la mejora de las comunicaciones interiores.

En efecto, las deficiencias y la carestía del transporte eran desde siempre importantes, como si los ríos españoles no ofreciesen las condiciones idóneas por los importantes desniveles así como de la irregularidad de sus cauces. Se entendió desde el siglo xvi que el transporte fluvial era una alternativa más económica y eficaz para el transporte de mercancías voluminosas, y Carlos III va, como su antecesor Fernando VI, a desarrollar entonces un intervencionismo creciente sobre el modelo francés ${ }^{21}$.

Sin embargo, la monarquía española no mostró, como su vecina francesa, tanta obstinación para defender sus privilegios y prerrogativas para ese tipo de ordenación. Al contrario, España, con una política más abierta para las concesiones de las obras, parecía querer atraer hacia ella a los ingenieros extranjeros que le faltaban en ese campo; el fracaso del canal del Manzanares bajo Fernando VI constituyó la prueba manifiesta de esa carencia. Es por eso por lo que se nota la presencia de ingenieros franceses como Charles Lemaur o Augustin Badin, para la realización de los proyectos de los canales de Castilla o de Aragón... La llegada de un ingeniero y arquitecto real francés como Mansart de Sagonne no podía más que satisfacer las esperanzas del rey. ¿No estaba ligada esa política liberal a las dificultades encontradas durante las obras de los canales de Castilla y del Norte cuya rapidez no podía evolucionar más que al ritmo de las dotaciones presupuestarias del Estado, que tenía entonces el encargo de su realización? Al confiar las obras a una firme compañía privada, la política de canalización de los ríos españoles de Carlos III evolucionará entonces más rápidamente y más económicamente para el presupuesto del país.

Parece también que la real administración española era mucho menos exigente que la francesa para la viabilidad de las compañías y para la fiabilidad de los proyectos: ¿Qué puede un consejo como el de Castilla, al que se pide registrar la voluntad del rey y cuyos conocimientos en ese campo son restringidos? La monarquía española puede ser tanto menos avara de sus prerrogativas cuanto que no tiene los medios financieros para defenderlos: confiar la construcción y la explotación de un canal durante un tiempo determinado, es el único medio que tiene para hacer evolucionar a España en el plano de las comunicaciones interiores.

\footnotetext{
${ }^{20}$ El caso del canal de Borgoña es muy significativo. Véase el estudio de Pierre Pinon: «La longue durée du canal de Bourgogne» en Un canal des canaux, CNMHS, Paris, 1986, pp. 289 a 299.

${ }^{21}$ Cuando Carlos III era rey de Nápoles, el padre Galiani, sacerdote napolitano, le había dedicado un «Diálogo sobre el comercio de los trigos» en el que se mostraba la necesidad de ordenar la naturaleza para cambiar la estructura económica de un país. Véase el artículo de Carlos Sambricio: «Urbanisme et territoire dans l'Espagne du xvine siècle: être maître de la nature dans la pratique», in Cahiers du CREPIF, n. ${ }^{\circ} 18$, marzo de 1987, p. 116
} 
De todas formas, está claro que los proyectos de Mansart son animados por la negociación del tratado de comercio entre Francia y España en 1767, y que se firmará en Madrid el dos de enero de 1768 en virtud del artículo 24 del tercer Pacto de Familia concluido entre S.M. Católica Carlos III y S.M. Muy Cristiana Luis XV en 1761 en París ${ }^{22}$. Ese tratado ratificado por ambas cortes al mes siguiente, aun cuando no trata sino del negocio marítimo, sin embargo constituye un magnífico impulso para el desarrollo de las estructuras económicas de España cuyas vías de comunicaciones (carreteras y canales de navegación) permiten una mejor penetración de las mercancías dentro del reino. Mansart de Sagonne conocía todo eso y fue por eso por lo que se alegró de ese nuevo impulso español y de sus extraordinarias perspectivas de desarrollo: pudo notar la presencia de numerosos ingleses, holandeses y alemanes incluso.

\section{Conclusión: Fracaso de los proyectos españoles de Mansart de Sagonne}

Por desgracia, como en Francia, Mansart no pudo llevar a cabo sus proyectos de canales. No logró probablemente todos los socios que necesitaba para su compañía: ¡sólo encontró a tres en Burdeos! Hemos visto que, a partir de 1770, el rey no tardó en cesar los derechos del canal del Manzanares aunque los había llegado a prometer a Mansart.

En ese fracaso, es muy posible que la fama del artista tuviese que sufrir con las diversas dificultades que había conocido en Francia tanto en sus asuntos personales como en sus diversos proyectos de canales. Después de su brillante presentación ante Carlos III y el marqués de Grimaldi, éstos quisieron informarse sobre el personaje. Ahora bien, las envidias y las rivalidades contra su persona no faltaban en la corte de Versalles. Es por eso por lo que hubo probables reticencias en el poder español para confiarle operaciones para el desarrollo económico del país. Su edad -57 años en 1768 - pudo ser también un obstáculo como alude en unas cartas, impidiéndole llevar a cabo sus proyectos.

No cabe duda, sin embargo, que su llegada excitó mucho la curiosidad de Carlos III y su gobierno: hombre de convicción y de progreso, espíritu ilustrado, Mansart de Sagonne dio lugar a que proyectos casi abandonados como el del Hospital General de Madrid y el del canal del Manzanares tomaran un nuevo impulso definitivo. En efecto, esos proyectos se vieron seguidos de decisiones casi inmediatas a su llegada. Por desgracia para él, el canal del Ebro se había traspasado a los señores Badin, aunque su proyecto correspondiera más a las opciones del rey en ese campo.

Se puede preguntar si ese proyecto, que conocían los ministros más importantes del gobierno de Luis XV - Choiseul y Saint-Florentin - por las cartas que les escribía Mansart, no entraba en sus intenciones para debilitar la potencia británica en el Mediterráneo. Nos impide contestar la falta de documentos. Pero la política de Choiseul en esa región - acercamiento con las potencias mediterráneas (España, Nápoles, Parma) con el Pacto de Familia en 1761; la compra de Córcega en 1768 a la República de Génova para fortalecer la posición estratégica de Francia- se habría arreglado bien con un proyecto como el de Mansart para perjudicar a los intereses ingleses en la región.

Sin embargo, ¿se puede deplorar la falta de ejecución de ambos canales del arquitecto francés, cuando los únicos canales realizados en España durante los siglos XVIII y xIX se abandonaron en provecho del ferrocarril? Así, Mansart de Sagonne habría visto ineluctablemente sus proyectos abandonados, caídos en las mazmorras de la historia, realizados o no...

${ }^{22}$ Mansart propondrá otra vez un proyecto de canal navegable al principado de Lieja, después del tratado de comercio con Francia en 1773. 


\section{Bibliografía complementaria}

Juan Helguera, Nicolás García Tapia y Fernando Molinero: El canal de Castilla, Junta de Castilla y León, Valladolid, 1988 Andrés Llaurado y Fábregas: La navigation intérieure en Espagne. IVe congrès international de navigation intérieure, Manchester, 1890.

Felipe Mora: Canalización del Manzanares, Jarama y Tajo para la navegación entre Madrid y Lisboa, Madrid, 1909.

David R. Ringrose: Los transportes y el estancamiento económico de España (1750-1850), Madrid, 1972.

Francisco Xavier de Cabanés: Memoria que tiene por objeto manifestar la posibilidad y facilidad de hacer navegable el río Tajo desde Aranjuez hasta el Atlántico, Madrid, 1829.

\section{NUEVOS HALLAZGOS ROMÁNICOS EN EL MONASTERIO DE SAN ZOILO DE CARRIÓN DE LOS CONDES (PALENCIA) ${ }^{1}$.}

En el mes de octubre de 1999 y durante unos trabajos en la iglesia barroca del que fuera priorato cluniacense y monasterio benedictino de San Zoilo de Carrión de los Condes, aparecieron diversos restos románicos que se añaden al espectacular descubrimiento de la portada occidental cuya valoración fue publicada en esta misma revista ${ }^{2}$.

Desde aquellas fechas se ha podido avanzar de modo considerable en el conocimiento de la realidad material de la desaparecida iglesia románica, cuestión sobre la que se continúa trabajando ${ }^{3}$. Sabemos que era un edificio de planta basilical, de tres naves, cada una de ellas con cuatro tramos, y un transepto no destacado en planta cuyo tramo de crucero muy probablemente fue coronado por un cimborrio. Asimismo fue dotada de una elaborada fachada occidental con dos torres que albergaba el panteón funerario de la poderosa familia Banu-Gómez de $\mathrm{Ca}$ rrión, espacio polivalente denominado con el ambiguo término de galilea.

Los trabajos de desenfoscado han puesto a la luz una buena parte del muro meridional románico reutilizado hasta el mismo arranque de la bóveda de cañón que cubría la nave de la Epístola del templo. Su exterior fue forrado a fines del siglo Xvi por la obra del nuevo claustro proyectado por Juan de Badajoz. Asimismo es visible buena parte del paramento septentrional ampliamente destruido al llevarse a cabo la gran portada barroca. Como era frecuente, a la hora de sustituir su vieja construcción románica, la comunidad benedictina carrionesa se rigió por un criterio esencialmente económico. De este modo la traza barroca contempló el máximo aprovechamiento del encintado mural del templo precedente, limitándose a derribar los intercolumnios, a tabicar ventanas y afeitar impostas, fustes y capiteles de los muros. Sabemos que los trabajos se extendieron a lo largo de buena parte del siglo xvII y que, como resultaba frecuente, la primitiva traza del edificio se fue desvirtuando (prescindencia de una segunda y es-

\footnotetext{
1 Con posterioridad a la entrega al consejo de redacción de $A E A$, este trabajo fue ampliado en la ponencia: «La sculpture des royaumes chrétiens du Nord-Ouest de la Péninsule Ibérique vers l'an 1100: la captation d'un modèle de portail monumental», Colloque International à l'occasion du 9ème centenaire du clôttre de Moissac (Moissac, 28-30 juin 2000).

${ }^{2}$ José Luis Senra: «La portada occidental recientemente descubierta en el monasterio de San Zoilo de Carrión de los Condes», Archivo Español de Arte, LXVII (1994), pp. 57-72.

${ }^{3}$ José Luis Senra: «Algunas notas sobre la desaparecida iglesia románica del priorato cluniacense de Carrión de los Condes», en: III Congreso de Historia de Palencia (Palencia 30-31 de marzo y 1 de abril de 1995), Palencia 1996, tomo IV, pp. 439-451. También: «Aproximación a los espacios litúrgico-funerarios en Castilla y León: pórticos y galileas», Gesta, XXXVI/2 (1997), pp. 122-144; «Estructuras occidentales en los reinos occidentales de la Península Ibérica», en: Les avant-nefs et les espaces d'accueil dans l'église entre le Ive et le xile siècle (Colloque International, Auxerre, 17-20 juin 1999) [Actas en prensa].
} 